This item was submitted to Loughborough's Institutional Repository (https://dspace.lboro.ac.uk/) by the author and is made available under the following Creative Commons Licence conditions.

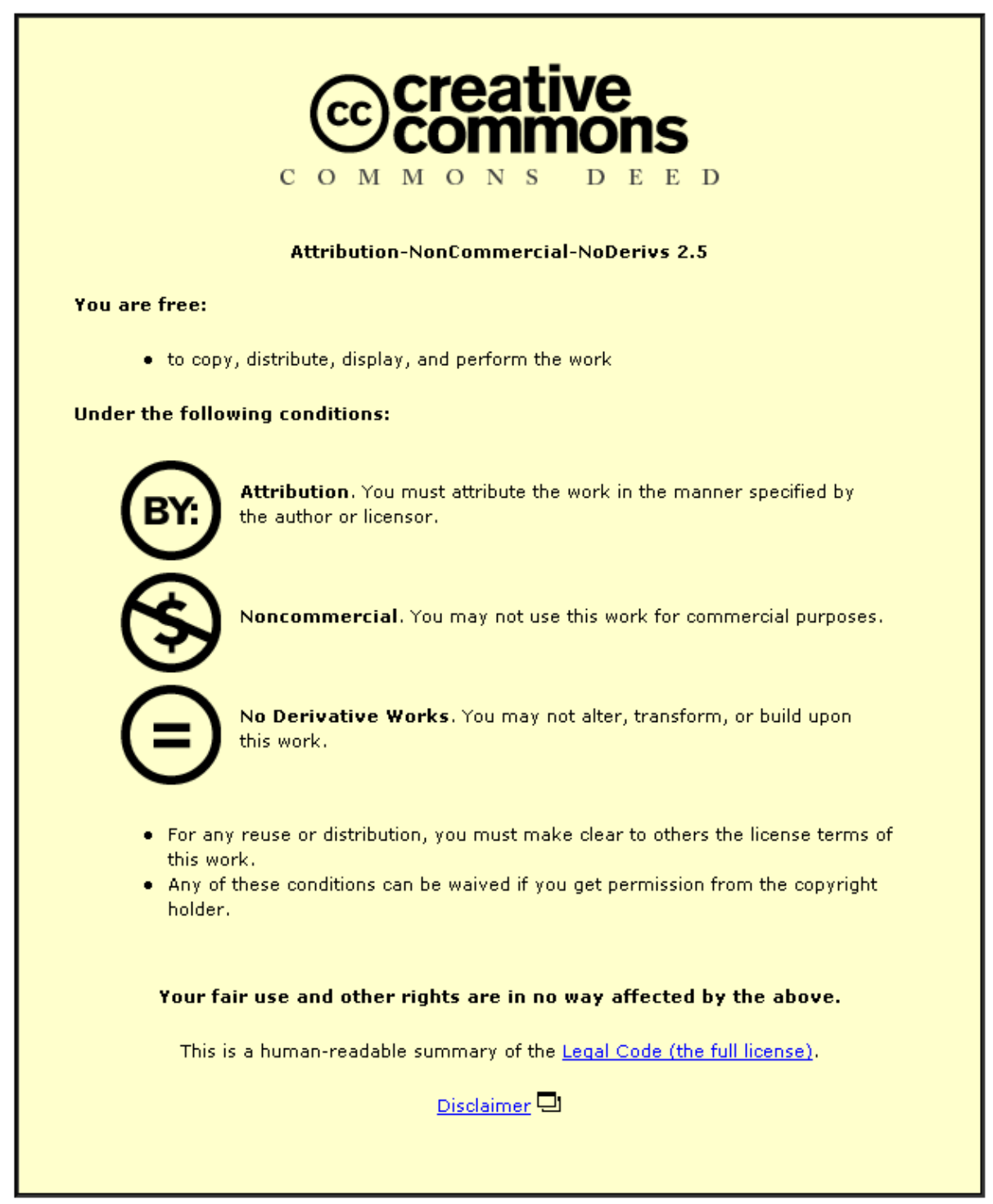

For the full text of this licence, please go to: http://creativecommons.org/licenses/by-nc-nd/2.5/ 


\title{
The Influence of Hole Orientation on the Aerodynamics of Battle Damaged Wings
}

\author{
Peter M. Render ${ }^{1}$ and Thomas W. Pickhaver ${ }^{2}$ \\ Department of Aeronautical and Automotive Engineering, Loughborough University, Loughborough, Leicestershire, \\ LE11 3TU, UK
}

Wind tunnel tests were carried out on an NASA LS(1)-0417MOD aerofoil with a circular hole simulating gunfire damage. To represent different attack directions, the inclination of the hole axis relative to the aerofoil chord was varied. The hole had a diameter of $20 \%$ of the aerofoil chord and its axis was centred at half chord. The aerofoil spanned the wind tunnel to create approximate two-dimensional conditions and balance measurements were carried out at a Reynolds number of 500, 000 . Surface flow visualisation and pressure measurements were also carried out. The aerofoil model incorporated a cavity to represent the internal geometry of an aircraft's wing. Compared to an undamaged wing the addition of damage increased drag, reduced lift and gave a more negative pitching moment. The effects increased with incidence. Adding negative obliquity, where the upper surface hole was moved forward and the lower hole rearwards, increased the magnitude of these effects. Except when combined with extreme negative obliquity, adding skew, where the holes were offset in a spanwise direction, had little measurable effect in terms of aerodynamic coefficients. However, adding skew introduced asymmetry to the flow through the damage.

\begin{tabular}{|c|c|c|}
\hline & & Nomenclature \\
\hline $\mathrm{C}$ & $=$ & chord \\
\hline $\mathrm{C}_{\mathrm{d}}$ & $=$ & drag coefficient \\
\hline $\mathrm{C}_{\mathrm{l}}$ & $=$ & lift coefficient \\
\hline $\mathrm{C}_{\mathrm{m}}$ & $=$ & pitching moment coefficient \\
\hline $\mathrm{C}_{\mathrm{p}}$ & $=$ & pressure coefficient \\
\hline $\mathrm{dC}_{\mathrm{d}}$ & $=$ & drag coefficient increment due to damage \\
\hline $\mathrm{dC}_{\mathrm{l}}$ & $=$ & lift coefficient increment due to damage \\
\hline $\mathrm{dC}_{\mathrm{m}}$ & $=$ & pitching moment coefficient increment due to damage \\
\hline $\mathrm{R}$ & $=$ & damage hole radius \\
\hline $\mathrm{x}$ & $=$ & co-ordinate along chord \\
\hline & & \\
\hline dam & & $=$ results for damaged model \\
\hline unda & & $=$ results for undamaged model \\
\hline
\end{tabular}

\footnotetext{
${ }^{1}$ Senior Lecturer. Senior Member AIAA

${ }^{2}$ Research Student
} 


\section{Introduction}

A ircraft survivability in a combat environment is an important aspect of the design process. Most survivability

assessments concentrate on structural and systems integrity, but it is known that aircraft can survive a significant level of damage and continue flying. In such cases there is a need to determine whether the aircraft can complete its mission, or instead should attempt to return to a friendly base. Information on the aerodynamic characteristics of battle damage that is required to make such an assessment, is currently lacking.

A systematic investigation into the aerodynamic effects of battle damage was carried out by Irwin ${ }^{1}$. This study investigated the effect of simulated gun fire damage on the two-dimensional characteristics of a NACA $64_{1}-412$ airfoil. The damage was modeled by circular holes with diameters ranging from $10 \%$ to $40 \%$ of airfoil chord. The influence of damage location was investigated by placing the damage centers at four different chord locations (leading, edge, quarter chord, half chord and trailing edge). For the quarter and half chord locations the key findings from Irwin's study were:

- $\quad$ Battle damage increased drag and reduced lift.

- The magnitude of any effect on pitching moment was dependent on hole location, but generally the addition of damage made pitching moment more negative (i.e. nose down).

- $\quad$ The above effects increased in magnitude with increasing incidence and hole size.

- The flow through battle damage was characterised as being either a weak or strong jet. A weak jet exited the damage hole and its wake attached to the aerofoil surface. Such jets resulted in small changes in lift, drag and pitching moment, and were associated with small holes or larger holes at low incidence. The strong jet exited the damage hole and penetrated into the freestream creating a large wake downstream of the damage. Strong jets resulted in large changes in aerodynamic forces and moments, and were associated with large diameter holes and small holes at high incidence.

One criticism that can be leveled against Irwin is his use of circular holes. However, Mani ${ }^{2}$ investigated the effect of hole shape and concluded that circular damage was a reasonable representation of the flow features and aerodynamic effects of more realistic damage shapes.

The present study looks to build upon Irwin's work by investigating the influence of damage hole orientation. Irwin simulated gunfire damage that was normal to the airfoil's chord line. In other words, the wing was hit by a shell or bullet which was fired from either directly below or directly above. In reality gun fire can come from a range of attack angles. An attack direction of ahead and below an aircraft is typical of anti-aircraft gun emplacements whilst attacks from above and behind are typical of cannon fire from enemy aircraft. Assuming that the entry and exit holes are of the same size reduces these two directions to effectively the same case.

\section{Model and Damage Modeling}

The NASA LS(1)-0417MOD airfoil was selected for the study since it is a more modern design than the NACA airfoil used by Irwin. The airfoil is also likely to be similar to those found on modern low speed aircraft such as Unmanned Air Vehicles (UAV). The tests were carried out on an airfoil model of $200 \mathrm{~mm}$ chord (c) and $450 \mathrm{~mm}$ span. Previous studies ${ }^{3}$ have shown that the presence of a cavity will have an influence on the aerodynamic effects of battle damage. For this reason the model had a hollow cavity between $0.24 \mathrm{c}$ and $0.75 \mathrm{c}$ to replicate the internal structure of an aircraft wing. A schematic view of the model construction is shown in Fig. 1. The leading and trailing edges of the model were solid and manufactured from ProLab 65 which is a synthetic modeling board. The top and bottom of the cavity were formed by removable panels. These panels were molded from fiberglass and attached to the model by countersunk screws. The cavity had a spanwise extent of $270 \mathrm{~mm}$ and was centered at mid span of the wing.

The simulated battle damage was added to the removable panel, with a new set of panels used for

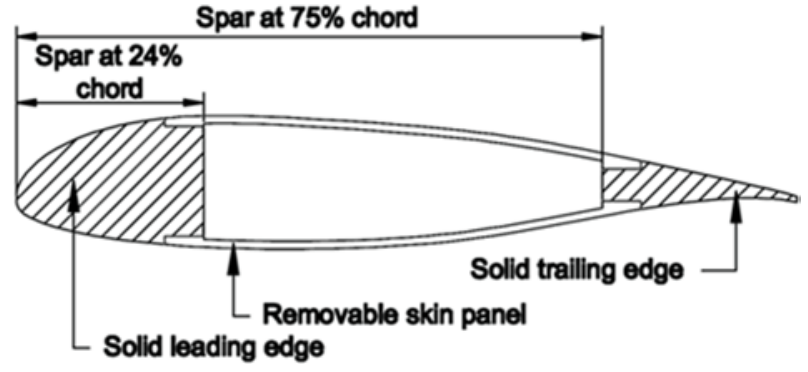

Figure 1. Sketch showing construction of wind tunnel model

each damage case tested. This paper concentrates on circular holes of $20 \%$ chord diameter with the holes centered at half chord and mid span of the model. The orientation of the damage was: 
a) Straight through with the holes on the upper and lower surface immediately above each other. (i.e.: the axis of the line joining the hole centers was normal to the airfoil chord.)

b) Positive and negative obliquity with the upper and lower surface holes displaced along the chord. (i.e.: the axis of the line joining the hole centers passed through the half chord location on the airfoil's chord, but was rotated fore and aft.) Negative obliquity resulted in the upper surface hole being closer to the airfoil's leading edge.

c) Skew with the upper and lower surface holes displaced along the span of the model. (i.e.: the axis of the line joining the hole centers passed through the chord at the model's mid span location but was rotated towards the model's tips.) Given the symmetry of two-dimensional testing there was no need to consider skew of opposite sign.

d) Combined skew and obliquity

Fig. 2 illustrates the definition of obliquity for $+60^{\circ}$. The black regions indicate the hole and the hatched regions indicate the solid leading and trailing edges. The dashed line indicates the chord line and the dash-dot line indicates the obliquity angle, centred on the chord line.

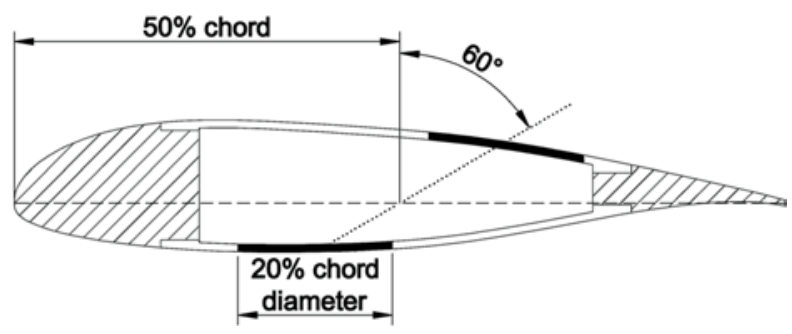

Figure 2. Sketch showing definition of $+60^{\circ}$ obliquity

\section{Experimental Technique}

The model was installed in a low turbulence wind tunnel so that it spanned the working section to create approximately two-dimensional conditions. All wind tunnel tests were run at a Reynolds Number of 500,000 although a transition strip was installed on the upper surface at $0.075 \mathrm{c}$ to minimise potential Reynolds number effects. The wind tunnel turbulence intensity was around $0.1 \%$.

A sketch of the wind tunnel installation is shown in Fig. 3. The model was mounted on to a balance beneath the working section by means of fore and aft struts. The mounting points for these struts lay outside the previously described removable panels and cavity. The balance measured lift, drag and pitching moment with calibrated accuracies of better than $0.05 \%$ full scale deflection for all components. Balance readings were recorded by a PC using LabView software and a National Instruments CompactRIO data acquisition system. Balance measurements were supplemented by surface flow visualisation obtained with a mixture of titanium dioxide, paraffin and linseed oil.

The $200 \mathrm{~mm}$ chord of the model was chosen to allow more precise damage modeling. However, this

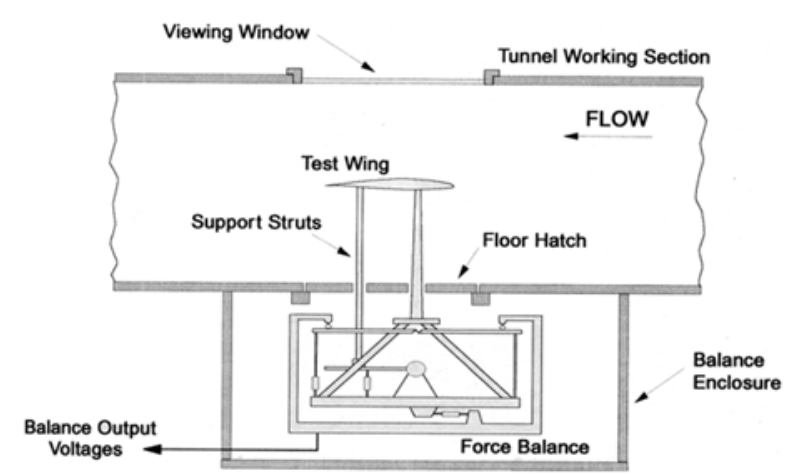

Figure 3. Experimental arrangement in wind tunnel

gave a chord to tunnel height ratio of 0.444 , which is significantly larger than the normally accepted maximum of 0.3 . Wind tunnel corrections were applied to balance measurements using the method of Garner ${ }^{4}$. The applicability of this method was established at the start of the study when wind tunnel tests were carried out on undamaged models of 200 and $141 \mathrm{~mm}$ at the same Reynolds number. The latter model gave a chord to tunnel height ratio of 0.3. Comparing the results from the two models indicated that the adopted wind tunnel corrections were valid for the $200 \mathrm{~mm}$ chord model.

Prior to carrying out damage investigations extensive studies were carried out to assess the repeatability of balance measurements. This was done by testing the model with undamaged panels. Although the panels were molded so that their external profile was accurate, they were laid up by hand. This produced small variations between panels. The influence of this variation was assessed during repeatability studies through testing all of the panels in their undamaged state. Overall the repeatability of the lift, drag and pitching moment coefficients determined from balance measurements were assessed as:

- $\mathrm{C}_{1}: \pm 0.018$

- $\mathrm{C}_{\mathrm{d}}: \pm 0.0016$ 
- $\mathrm{C}_{\mathrm{m}}: \pm 0.0021$.

Repeatability checks on different damage cases confirmed that these repeatability levels were applicable for all balance measurements.

Prior to investigating damage, the accuracy of the undamaged model was assessed by comparing with published NASA data obtained from wind tunnel tests ${ }^{5}$. The NASA data was collected at a Reynolds number of 2,000,000 and coefficients were obtained from pressure rather than balance measurements. Experience suggests that there are often small differences between coefficient data obtained from the two methods. For example, drag coefficients measured by a force balance have a tendency to produce higher values than pressure measurements. There was also a significant difference between the two models, since the NASA model had a smooth and continuous profile, whilst the current model had panels, which despite fitting well, produced discontinuities in the model surface. The differences between the present study and NASA data was consistent with the noted differences, and indicated that acceptable data was produced by the present arrangement.

Following balance and flow visualisation runs, some of the removable panels were pressure tapped to provide surface pressure measurements at $0^{\circ}$ and $8^{\circ}$ incidence. On each panel, ten chordwise tappings were placed at fixed intervals of $10 \mathrm{~mm}$ in each of five spanwise locations, These locations were defined relative to a straight through hole and located at $0 \mathrm{R}, 0.5 \mathrm{R}, 1.5 \mathrm{R}, 2.5 \mathrm{R}$ and $5 \mathrm{R}$, from the hole center, where ' $\mathrm{R}$ ' is the radius of the damage hole. The tappings were connected to an array of four Pressure Systems 16TC/DTC pressure scanners linked to a PC via a Chell CANdaq data acquisition unit. The data acquisition software sampled each pressure tapping 8,192 times over a period of approximately 30 seconds. The nominal accuracy of the pressure scanner was $\pm 0.0696 \mathrm{mmH}_{2} \mathrm{O}$.

For ease of comparison, the results for the damaged cases are presented as changes from the undamaged lift, drag and pitching moment coefficients. The changes, or increments, are defined as

$$
\begin{gathered}
\mathrm{dC}_{\mathrm{l}}=\mathrm{C}_{\mathrm{l} \text { damaged }}-\mathrm{C}_{\mathrm{l} \text { undamaged }} \\
\mathrm{dC}_{\mathrm{d}}=\mathrm{C}_{\mathrm{d} \text { damaged }}-\mathrm{C}_{\mathrm{d} \text { undamaged }} \\
\mathrm{dC}_{m}=\mathrm{C}_{\mathrm{m} \text { damaged }}-\mathrm{C}_{\mathrm{m} \text { undamaged }}
\end{gathered}
$$

\section{Straight Through Damage}

The lift coefficient increments due to straight through damage are shown in Fig. 4. The zero lift incidence of the aerofoil was $-2.5^{\circ}$, and below this incidence the flow through the damage hole was reversed and led to an increase in lift. In other words there was a reduction in the negative lift produced by the undamaged aerofoil. As incidence was increased the lift loss also increased, until it started to decline at incidences greater than $10^{\circ}$. At this point the aerofoil was close to stall and there was significant separated flow on the upper surface. The increase in lift loss with incidence was associated with the strengthening of the jet flow through the damage and is illustrated by the flow visualisation pictures shown in Fig. 5. The leading edge of the model is towards the bottom of each picture. To avoid contamination of the transition strip the flow visualisation mixture was applied downstream of the strip. At zero degrees incidence

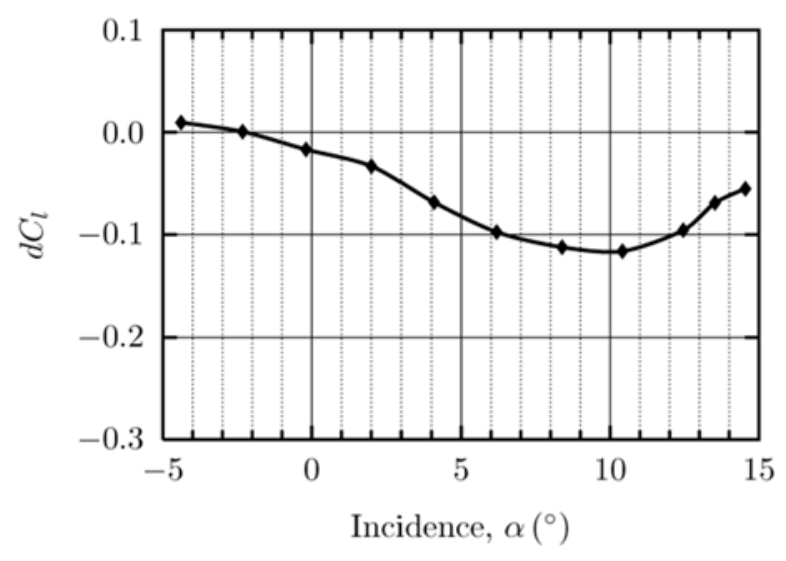

Figure 4. Lift coefficient increments for straight through damage

(Fig. 5a) the damage flow produced a wake behind the hole which was attached almost up to the trailing edge where the flow visualisation mixture had collected as a white area. This collection of mixture indicates flow separation. Forward of the hole there was little indication of the flow over the forward part of the model being diverted around the hole, the damage jet and its wake. This indicates that there was relatively little flow through the damage hole. Increasing the incidence to $2^{\circ}$ (Fig. 5b) resulted in a more significant flow structure. The presence of a clearly defined forward separation line (A), where the flow over the forward part of the model was diverted around the 


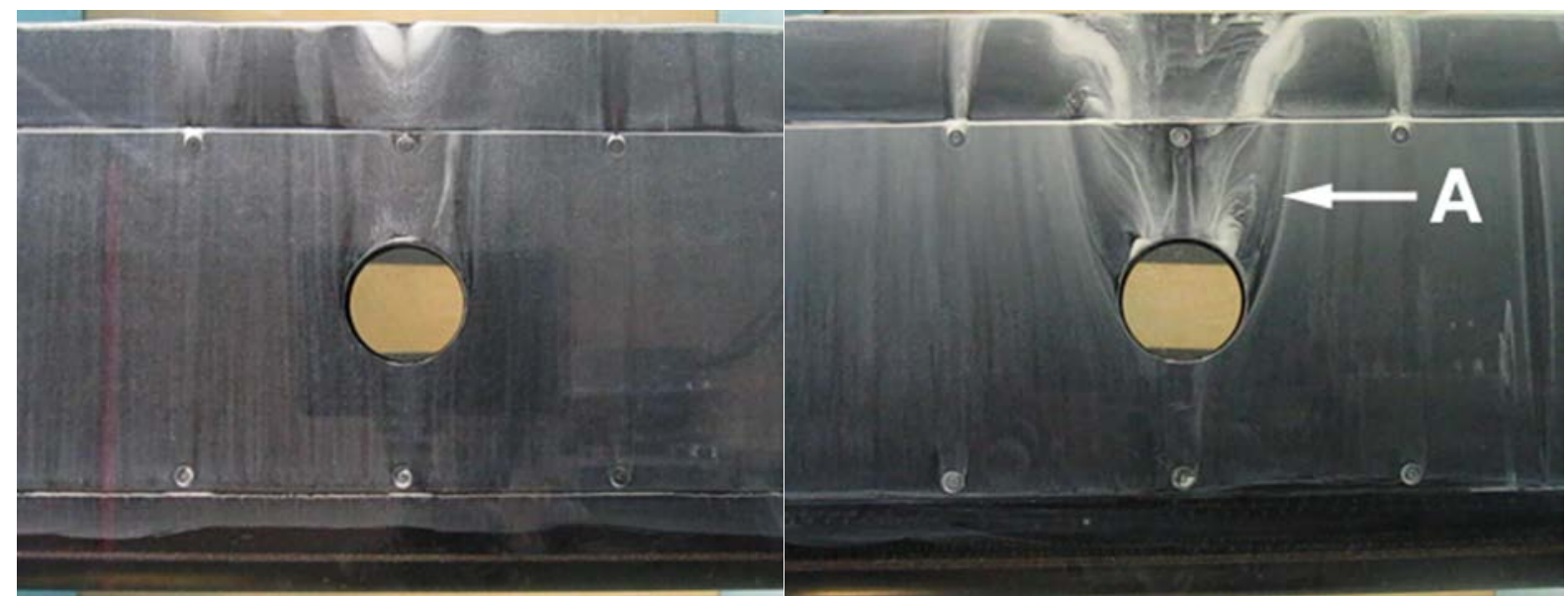

a) $0^{0}$ Incidence

b) $2^{0}$ Incidence

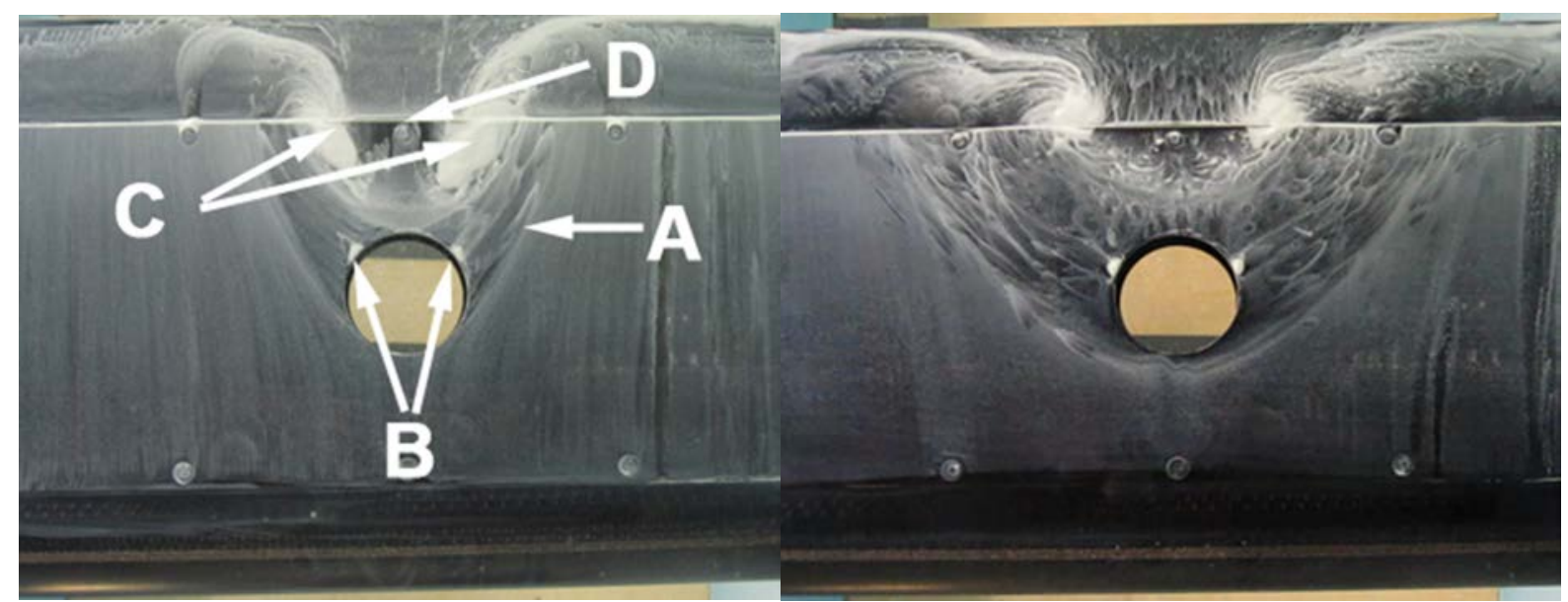

c) $4^{0}$ Incidence

d) $8^{0}$ Incidence

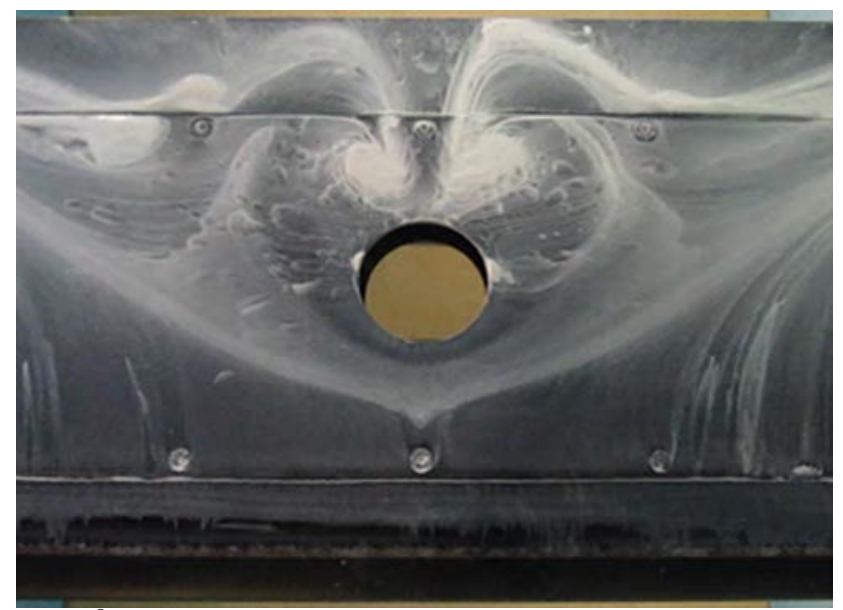

e) $12^{0}$ Incidence

Figure 5. Flow visualisation on upper surface of model for straight through damage

damage jet and its wake, indicates a strengthening of the jet. The increased size of the wake behind the damage also indicated increased jet strength. At $2^{\circ}$ the damage flow was well on the way to becoming a strong jet and by $4^{\circ}$ (Fig. 
5c) exhibited all of the expected features of a strong jet. The flow around the model's leading edge was diverted around the damage jet and its wake at the forward separation line (A). On the downstream edge of the damage hole there was a pair of contra rotating vortices which are a characteristic of jets in cross flows (B). Between two large contra rotating vortices (C) was a region of reverse flow (D) that was entrained around the trailing edge of the model. This flow moved towards the hole until it met the damage jet expanding downstream of the hole. At this point the reverse flow separated from the model's surface and was entrained into damage jet. This transition from weak to strong jet resulted in a significant change in the lift coefficient increments and was responsible for the change in gradient at around $2^{\circ}$ shown in Fig. 4.

Increasing incidence from $4^{\circ}$ to $8^{\circ}$ resulted in a strengthening of the damage jet and an increased disturbance to the flow over the upper surface of the model (Fig. 5d). This increased disturbance confirmed the increased lift loss seen in Fig. 4. At $12^{\circ}$ incidence, Fig. 5e shows that there was significant flow disturbance over much of the model surface. This disturbance which appears to be forward and to the sides of the hole was seen for the undamaged aerofoil at $12^{\circ}$ and was attributed to interaction between the flow at the model tips (i.e. at the tunnel side walls) and separated flow over the upper surface of the model. Behind this disturbance, the strong jet structure still existed beyond the damage hole, but it was smaller in extent than at $8^{\circ}$. This reduced extent confirmed the trend seen in Fig. 4 of reducing lift loss as the stall was approached.

The drag coefficient increments are shown in Fig. 6. At all incidences the damage resulted in an increased drag coefficient. As could be anticipated from the flow visualisation shown in Fig. 5, the drag coefficient increased as the incidence was increased above the zero lift angle, before decreasing as the stall was approached. The increase in drag was fairly consistent, and there was no significant changes brought about by transition from weak to strong jet.

The pitching moment coefficient increments are shown in Fig. 7. At negative incidences the increment was positive, but became increasingly more negative as incidence was increased. Once again the trends in the increments changed as stall was approached. The negative increments were suggested by the pressure distributions measured on the panels. Fig. 8 shows the

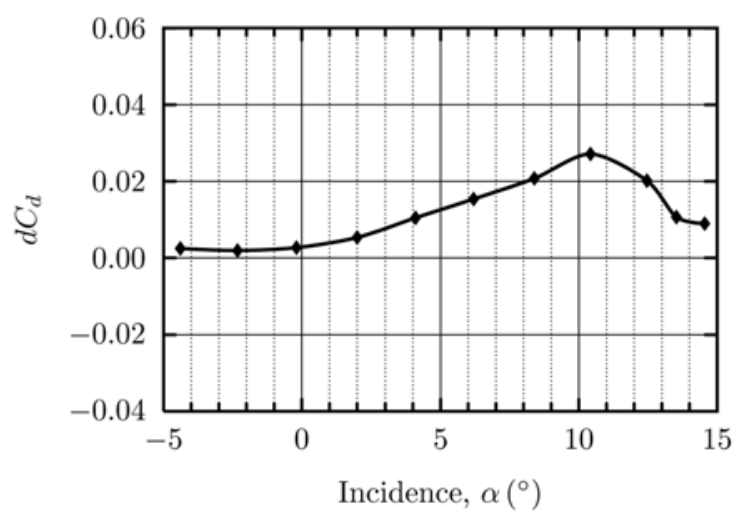

Figure.6. Drag coefficient increments for straight through damage

pressure coefficients $\left(C_{p}\right)$ for both the undamaged and damaged panels at $8^{\circ}$. The undamaged distribution is only shown for the mid span location $(\mathrm{R}=0)$, since the flow over the model was two-dimensional. For the damaged panel there was a reduction in the magnitude of the pressure coefficients for both the upper and lower surfaces, except for a small region towards the rear of the upper panel. In front of the damage there was a significant decrease in the magnitude of the negative $C_{p}$, which suggests there was a large reduction in the suction peak at the leading edge of the model. A similar reduction in the pressure peak was seen by $\operatorname{Irwin}^{1}$ when he pressure tapped an aerofoil with damage at quarter chord. This reduction was primarily responsible for the reduced pitching moment seen in Fig. 7 at $8^{\circ}$. This effect of the reduced suction peak was partially offset by the changes in $\mathrm{C}_{\mathrm{p}}$ behind the quarter chord position, which was the reference centre for pitching moment. However, the increased magnitude of pressure coefficient at around $\mathrm{x} / \mathrm{c}=0.7$ would have extended to the trailing edge of the model and contributed a negative pitching moment.

Compared to the undamaged case, the pressure distributions for the damaged upper panel showed reduced magnitude of $C_{p}$ forward of the damage hole indicating that the flow over the leading edge of the

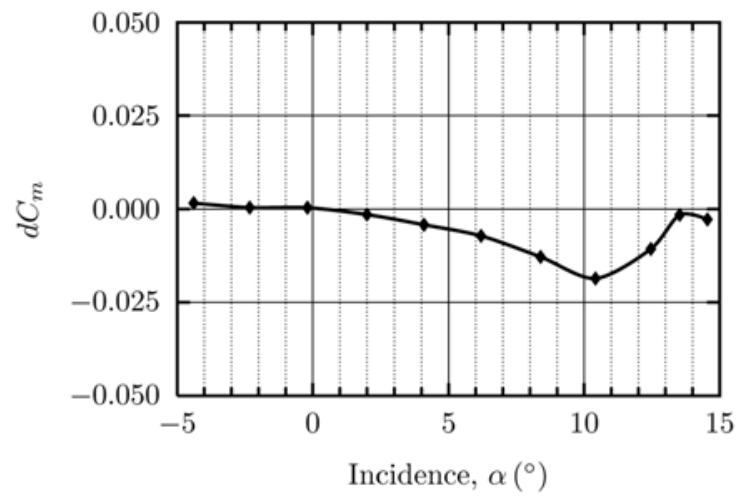

Figure 7. Pitching moment coefficient increments for straight through damage

aerofoil slowed down as it approached the damage jet, This retardation was evident at $\mathrm{R}=5$ for the whole panel length, although flow visualisation (Fig. 5d) indicated that this station was outside any damage flow features. Near the sides and downstream of the hole the upper surface $C_{p}$ distributions were largely invariant along the chord, 
indicating that there was little flow acceleration around and downstream of the hole. The failure of the $\mathrm{C}_{\mathrm{p}}$ values downstream of the hole to return to undamaged values is a feature of strong jets and has been noted by $\operatorname{Irwin}^{1}$. On the lower surface, the presence of the damage resulted in reduced $C_{p}$ values for all tapping locations, although the shape of the curves remained similar to the undamaged case. The exceptions were for $\mathrm{R}=0$.and 0.5 where changes in $\mathrm{C}_{\mathrm{p}}$ occurred both upstream and downstream of the hole. The reduction in $\mathrm{C}_{\mathrm{p}}$ forward of the hole indicated significant flow acceleration into the hole. Downstream of the hole the $\mathrm{C}_{\mathrm{p}}$ values were little changed from the undamaged case. Flow visualisation on the lower surface revealed that the rear of the damage hole behaved like a cavity with a small attached wake whose width was approximately the diameter of the hole. These measurements coincided with this cavity wake.

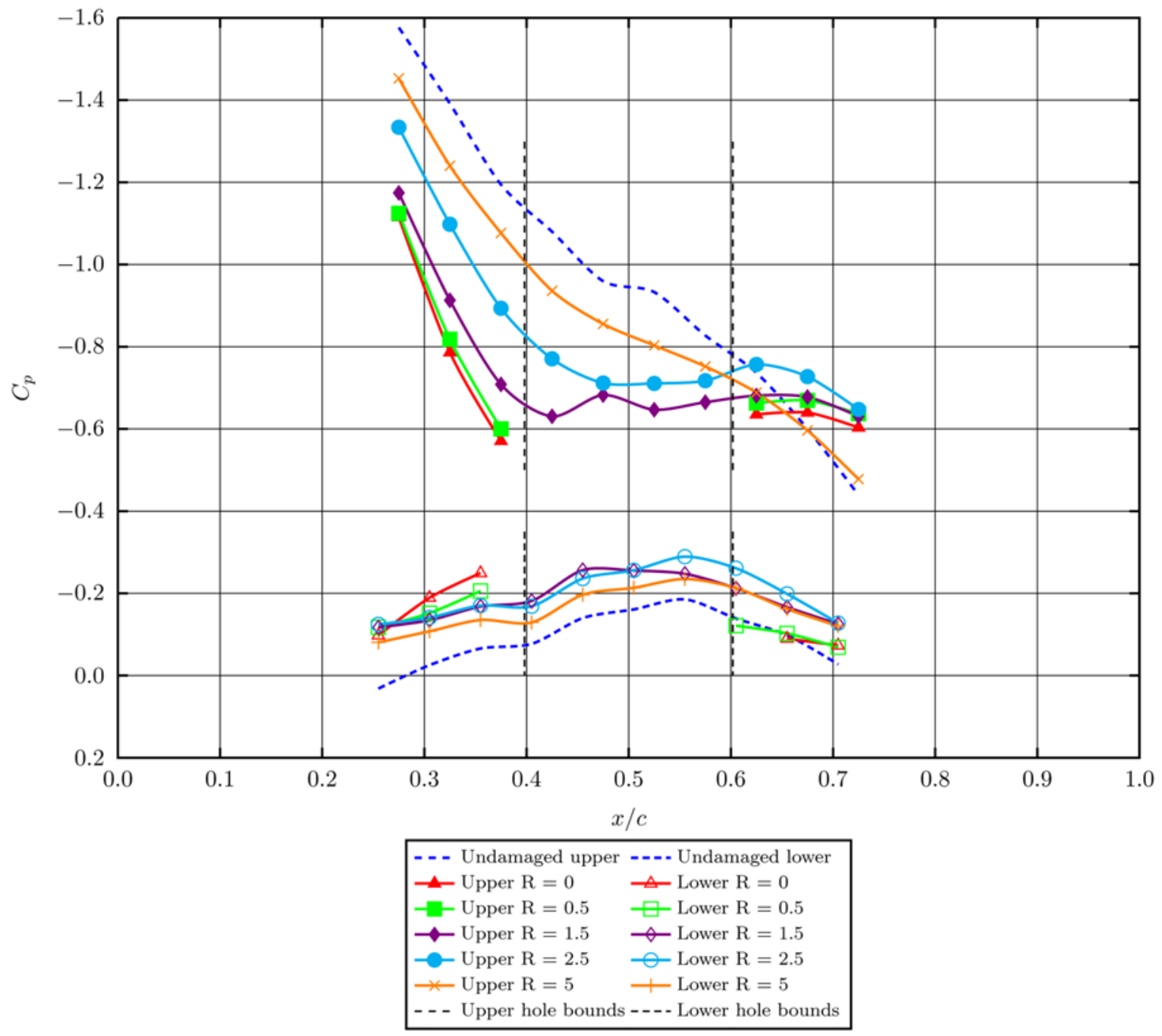

Figure 8. Pressure coefficient distributions at different spanwise locations for straight through damage

\section{The influence of obliquity}

Changing obliquity had a marked effect on the flow through the damage as is clearly shown in Fig. 9. The five pictures are arranged in $30^{\circ}$ steps of obliquity from $+60^{\circ}$ to $-60^{\circ}$ and show the upper surface of the model at an incidence of $8^{\circ}$. Figure $9 \mathrm{c}$ is the straight through case previously shown as Fig. $5 \mathrm{~d}$. This sequence of pictures is a vivid illustration of how the jet strength and the extent of the flow disturbance increased as the obliquity became more negative. This increasing jet strength was evident at all incidences and can be attributed to the increased differential pressure across the damage hole as obliquity was increased. Table 1 shows the differential pressure coefficients $\left(\mathrm{dC}_{\mathrm{p}}\right)$ across the centers of the upper and lower surface holes for three obliquity angles. These values 


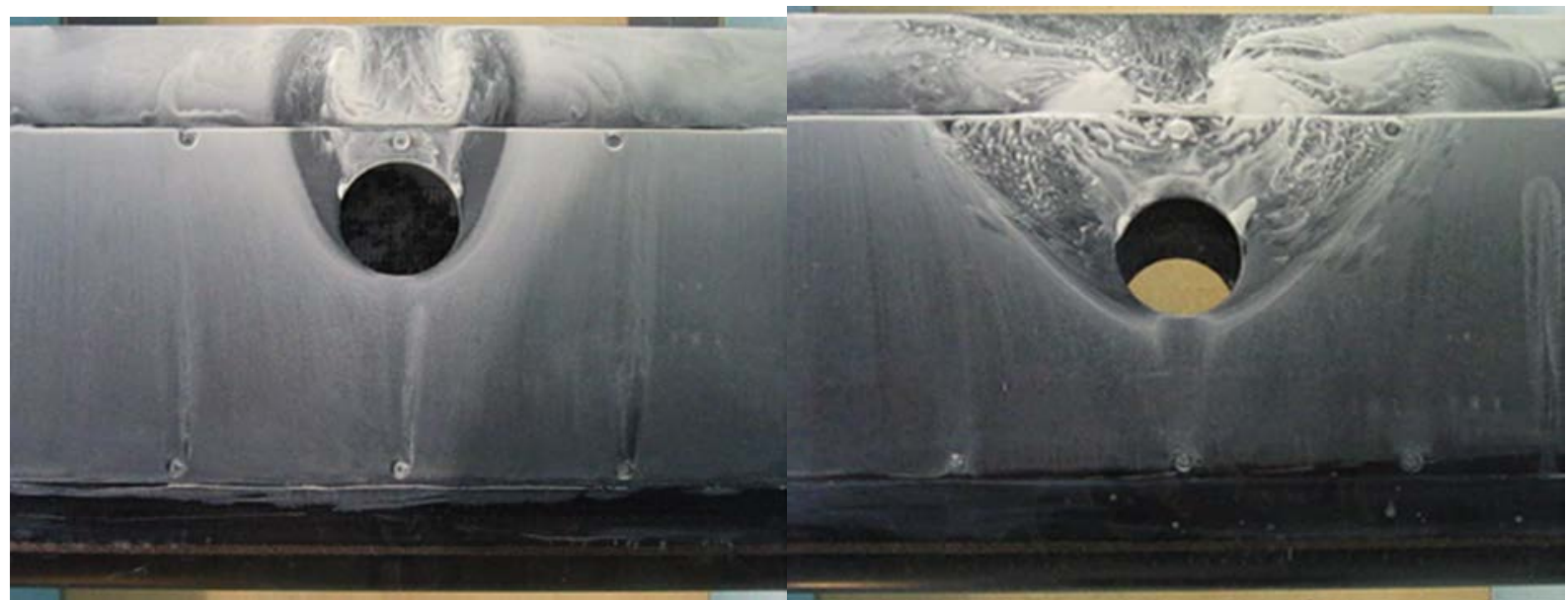

a) Obliquity $=60^{\circ}$

b) Obliquity $=30^{\circ}$

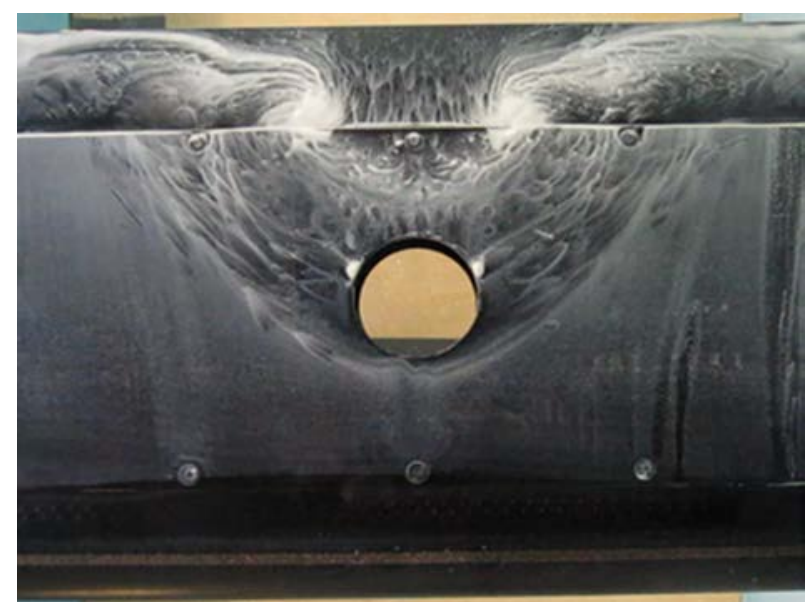

c) Obliquity $=0^{\circ}$

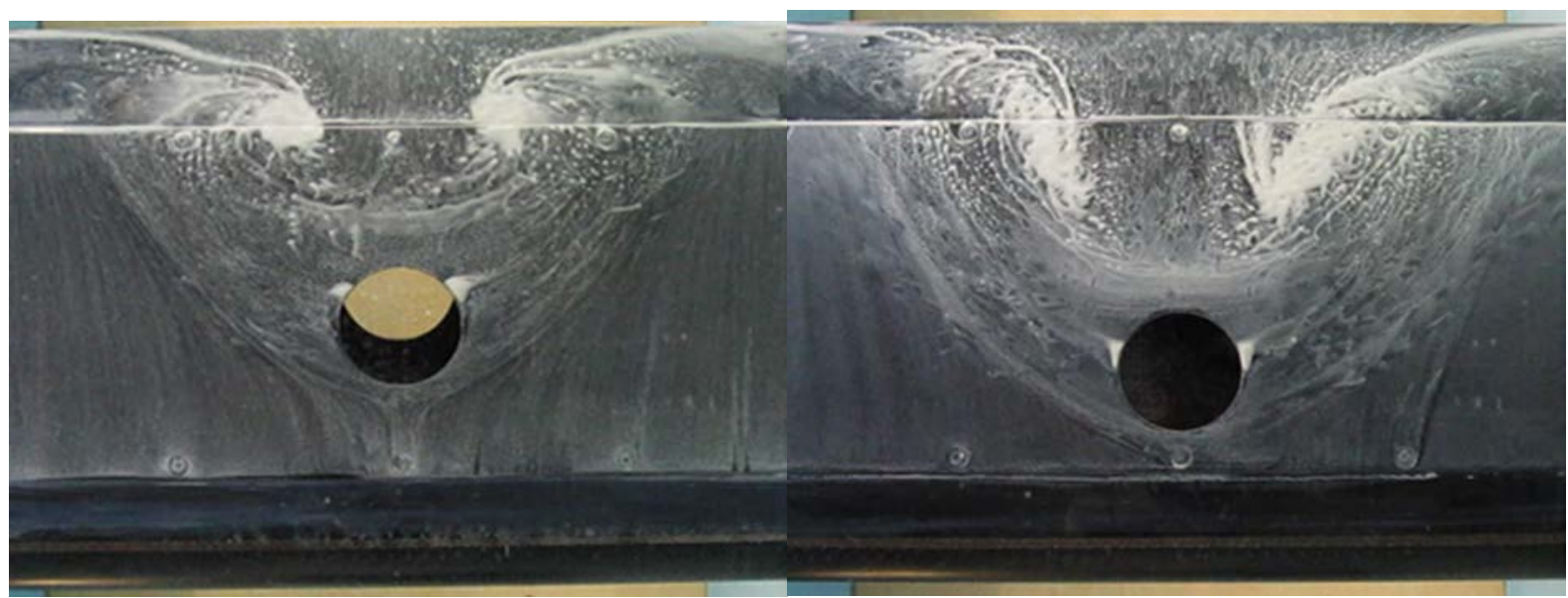

d) Obliquity $=-30^{\circ}$

e) Obliquity $=-60^{\circ}$

Figure 9. Flow visualisation on upper surface for different obliquity angles. Incidence $=8^{\circ}$

of $\mathrm{dC}_{\mathrm{p}}$, which are for an incidence of $8^{\circ}$, were determined from the undamaged pressure distributions shown in Fig. 8. The undamaged differentential pressure coefficient can be seen to have increased as the obliquity angle became 


\begin{tabular}{|l|l|l|l|}
\hline & $\mathbf{- 6 0}^{\circ}$ obliquity & $\mathbf{0}^{\circ}$ obliquity & $\mathbf{+ 6 0}^{\circ}$ obliquity \\
\hline $\begin{array}{l}\text { Pressure coefficient differential at hole } \\
\text { center, } \mathrm{dC}_{\mathrm{p}}\end{array}$ & -1.20 & -0.80 & -0.61 \\
\hline
\end{tabular}

Table 1. Undamaged pressure coefficient difference at damage centers. Incidence $=\mathbf{8}^{\mathbf{0}}$.

more negative (i.e. the upper surface hole moved towards the leading edge of the panel). The undamaged pressure differential is believed to be a key indication of jet strength through the damage.

Based on the flow visualisation it was anticipated that reducing the obliquity from $+60^{\circ}$ would result in a reduction in lift coefficient and an increase in drag coefficient at any given incidence. This is confirmed by the coefficient increments shown in Figs. 10 and 11. For completeness, Fig. 12 shows the pitching moment coefficient increments. For all increments there were broadly three regions. At the lowest incidences the damage flow for all cases was a weak jet and the increments were similar for all obliquity angles. The onset of strong jet flow marked the start of the second region. For the $-60^{\circ}$ obliquity case the transition to strong jet flow occurred at around $0^{\circ}$ of incidence whilst this was delayed to $4^{\circ}$ for $+60^{\circ}$ obliquity With the strong jet established, the increments became larger and a distinct trend developed with obliquity. As the stall was approached (at around $12^{\circ}$ ) and exceeded, the trends with obliquity were less well defined. This represents the third
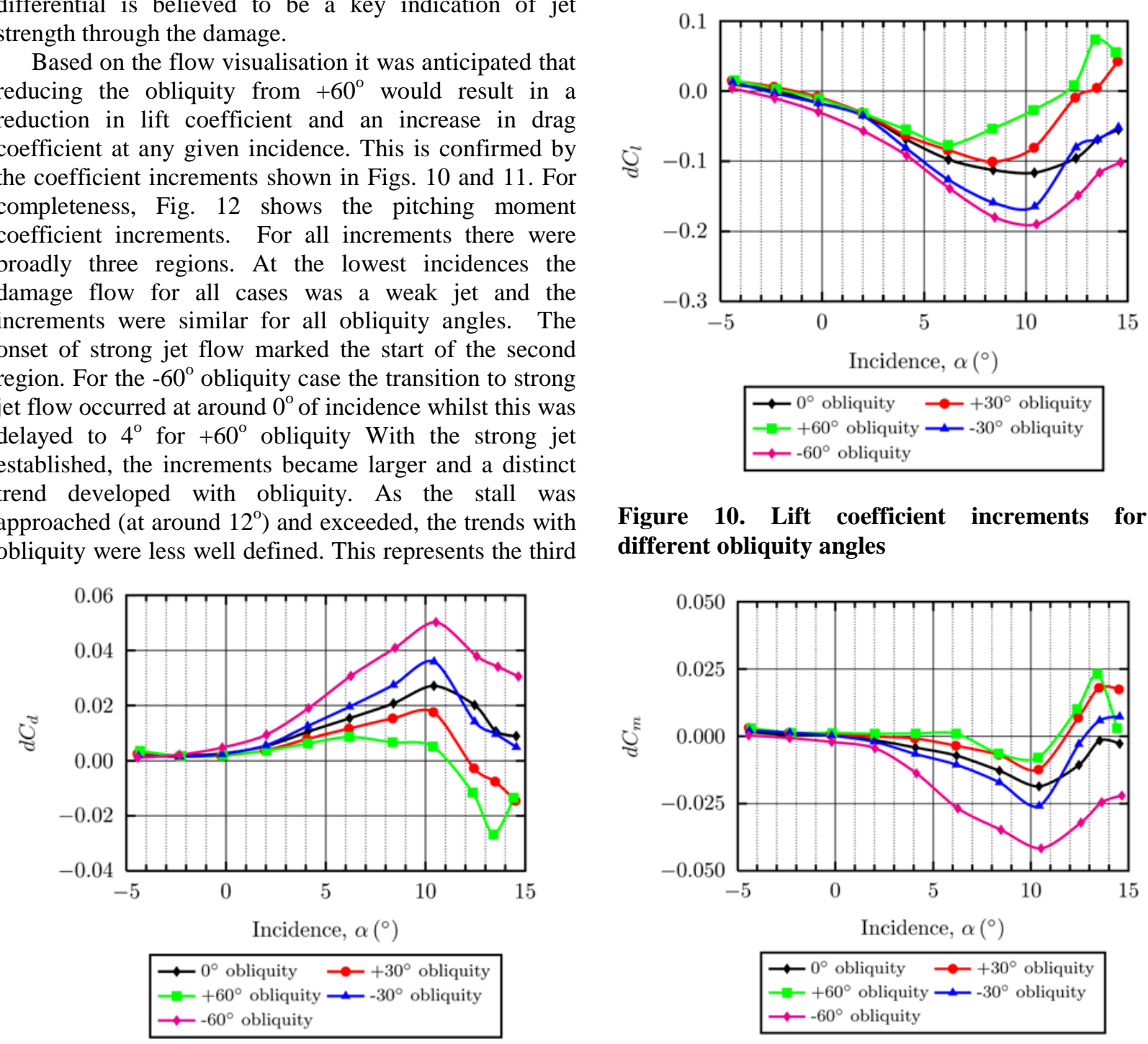

Figure 10. Lift coefficient increments for different obliquity angles

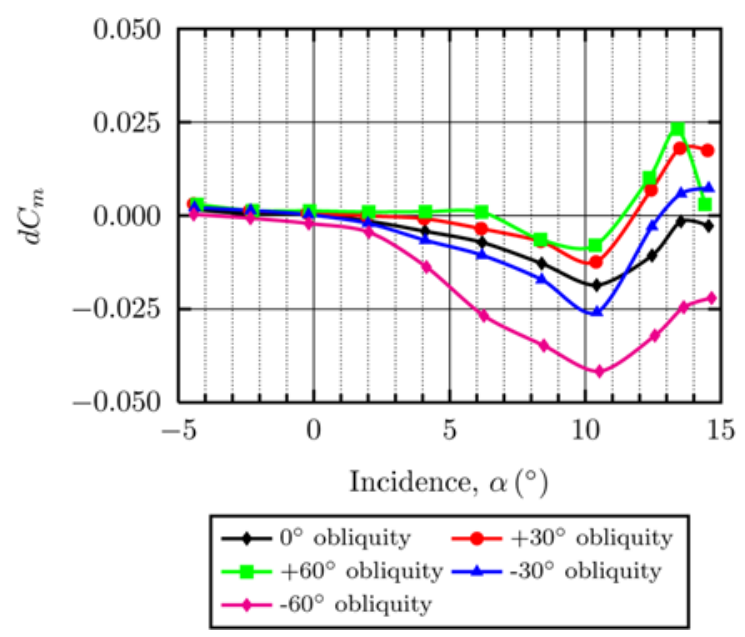

Figure 11. Drag coefficient increments for
different obliquity angles

Figure 12. Pitching moment coefficient increments for different obliquity angles

region and the lack of consistent trends can in part be attributed to the large extent of separated flow over the model causing increased repeatability errors.

The behavior of the $+60^{\circ}$ obliquity case is noteworthy as its behavior was not always consistent with the other cases. In Fig. 10 increasing the incidence from around $6^{\circ}$ to $12^{\circ}$ resulted in a decrease in the magnitude of $\mathrm{dC}_{l}$ for the $+60^{\circ}$ case. This was notably different from the other cases which showed increases in the magnitude up to typically $10^{\circ}$. Examination of the drag coefficient increment in Fig. 11 shows almost constant values for $+60^{\circ}$ obliquity between $6^{\circ}$ and $10^{\circ}$ rather than the increase shown by the other cases. For the pitching moment coefficient increments (Fig. 12) the effects were more subtle, but it can be observed that the $+60^{\circ}$ obliquity case crossed the 


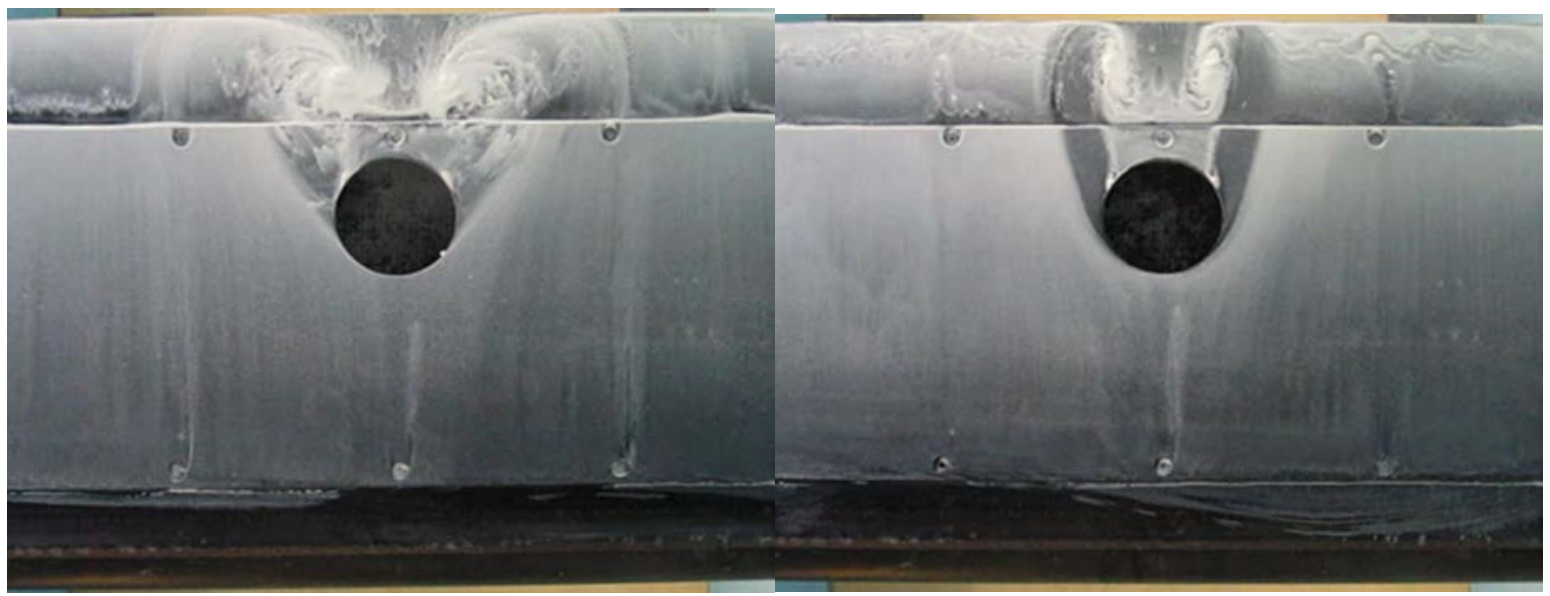

a) Incidence $4^{0}$

b) Incidence $6^{0}$

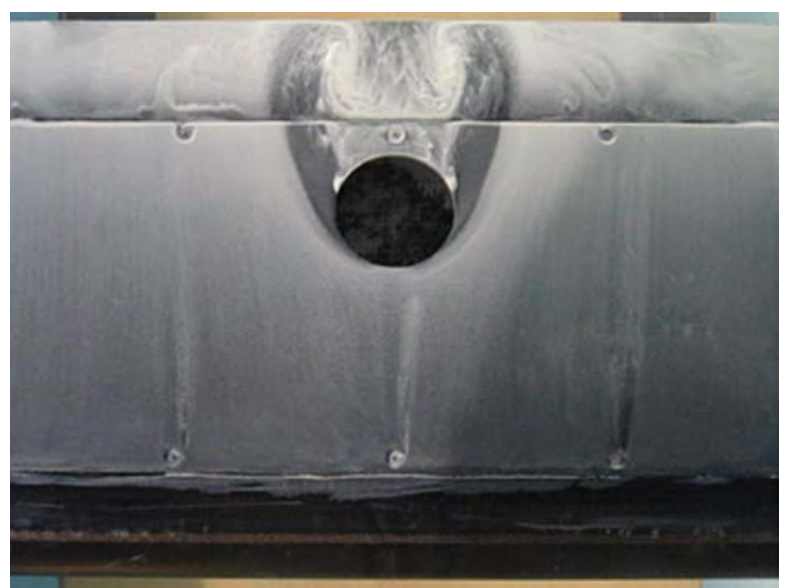

c) Incidence $8^{0}$

\section{Figure 13. Flow visualisation on upper surface for $60^{\circ}$ obliquity}

$+30^{\circ}$ curve at $8^{\circ}$ incidence. The behavior of the $+60^{\circ}$ obliquity case can be explained by flow visualisation. Figure 13 shows the upper surface for incidences of $4^{\circ}, 6^{\circ}$ and $8^{\circ}$. At $4^{\circ}$ the damage flow was a strong jet. At $6^{\circ}$ the jet appeared to weaken since the extent of the wake was visibly smaller. The jet remained in this state for further increases in incidence. This behavior was shown to be repeatable and only occurred for the $+60^{\circ}$ obliquity case. At the time of writing, the cause of the reducing jet strength has not been fully identified.

Surface pressure measurements were carried out for the $\pm 30^{\circ}$ obliquity cases and are shown in Fig. 14 . The pressure measurements are for an incidence of $8^{\circ}$, with results for the damage center line in Fig. 14a and those for $\mathrm{R}=2.5$ in Fig. 14b. For completeness measurements for the undamaged and straight through damage cases are also shown. In Fig. 14a the front edge of the damage hole is at $x / c=0.34$ for $-30^{\circ}$ obliquity, and $x / c=0.45$ for $+30^{\circ}$. The trends in the pressure measurements previously described for the straight through damage were applicable to the obliquity cases. For example on the centerline (Fig. 14a) of the upper panel, all of the cases showed a deceleration in the flow approaching the hole. This deceleration was more rapid as the obliquity became more negative and the upper surface hole moved forward along the wing. For all three cases the $C_{p}$ values immediately forward of the holes were similar, indicating that the damage jet was running full and occupying the full area of the hole. Downstream of the holes the $C_{p}$ values showed little variation which indicated the presence of a strong jet. From flow visualisation this is known to be in the damage wake and comprised of the damage jet expansion downstream of the hole and reverse flow from the trailing edge. The influence of obliquity was that the $C_{p}$ values became more negative as obliquity became more negative. On the damage centerline for the lower surface there was little significant effect of varying obliquity, Fig. 14b shows that the influence of obliquity continued to the sides of the damage and indicates that a reduction in lift occurred for a significant distance either side of the damage, regardless of the obliquity angle. Moving to negative obliquity reduced the leading edge pressure peak on the upper surface and 


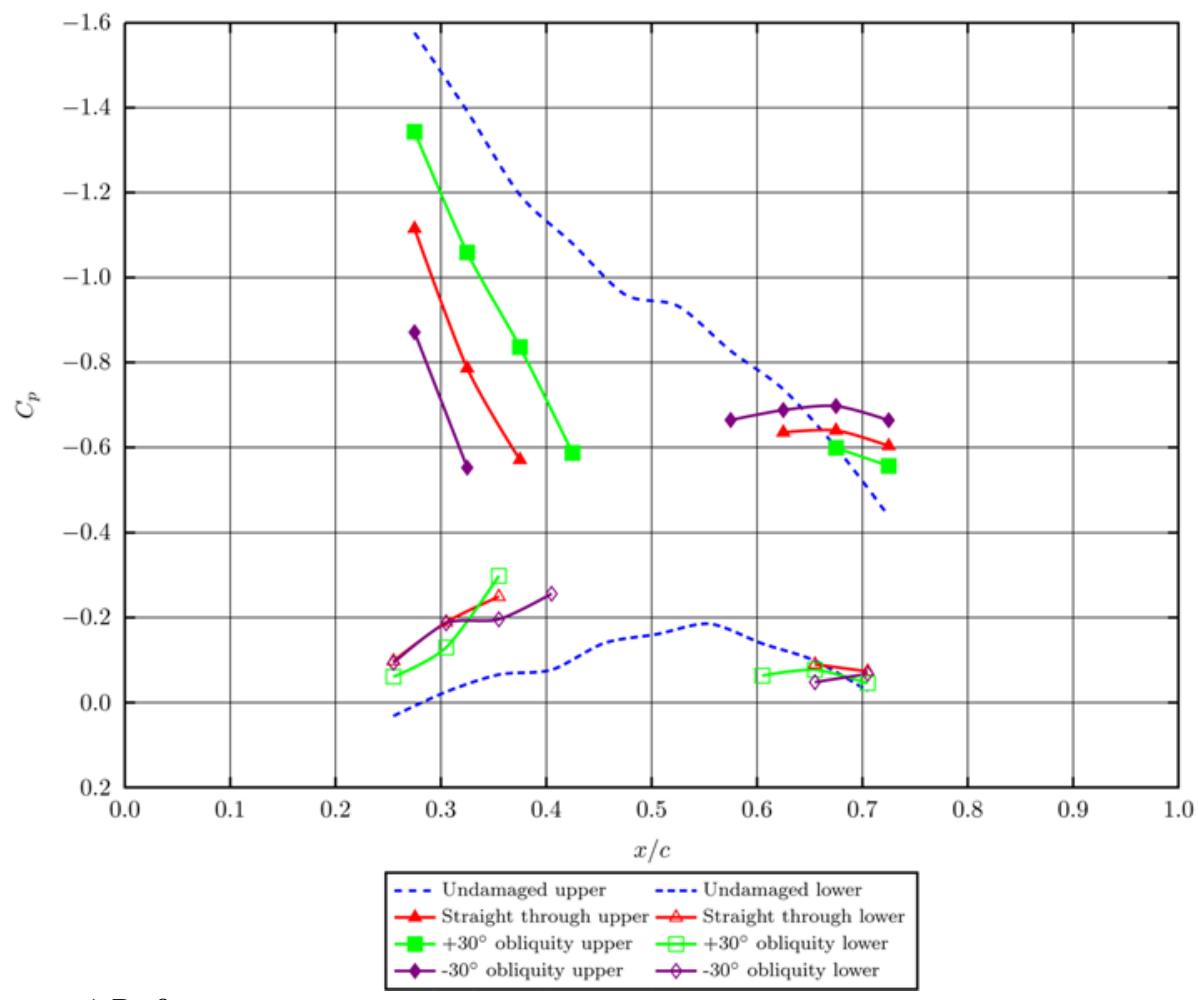

a) $\mathrm{R}=0$

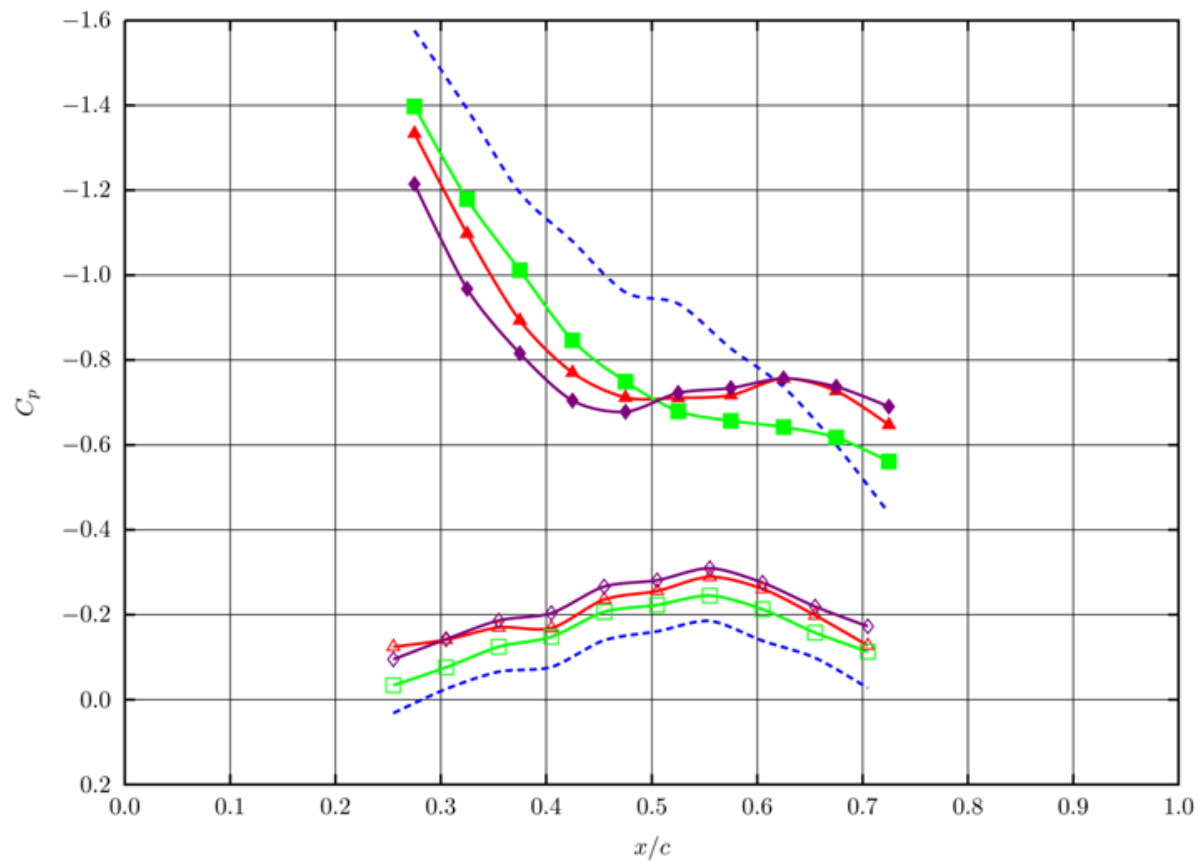

b) $R=2.5$

Figure 14. Surface pressure measurements for obliquity $\pm 30^{\circ}$

introduced a region of constant pressure through the damage wake. For $+30^{\circ}$ obliquity, the upper surface $\mathrm{C}_{\mathrm{p}}$ curve crosses the other two cases. This is consistent with the smaller wake from the reduced jet strength at positive obliquity. On the lower surface, all damage cases reduced the $\mathrm{C}_{\mathrm{p}}$ from the undamaged values, with the general trend of reducing obliquity increasing the effect. 


\section{The Influence of Skew}

As well as being subjected to attacks from in front and behind, it is also possible for an aircraft to be attacked from either side. This gives rise to the possibility of damage holes being skewed along the span of the wing. Given the two-dimensional nature of the wind tunnel tests, skewing the holes was expected to have little effect on the pressure differential across the hole, and the effects on the coefficient increments were expected to be small. This was confirmed by the coefficient increments shown in Figs 15 to 17, where there was little effect from skew until the onset of stall. Whilst skew had little effect on the measured increments, it did introduce asymmetry into the flow at all incidences. This is illustrated by Fig. 18 for a skew angle of $45^{\circ}$ and an incidence of $8^{\circ}$. This picture can be directly compared with the straight through case in Fig. 5d. Both pictures show jets of comparable strengths, but the skew case is asymmetric. This is most clearly seen by looking at the relative locations of the large contra rotating vortices. For the skew case the vortex on the right hand side is on the edge of the panel whilst the vortex on the left hand side lies between the panel and the wing trailing edge. This asymmetry is believed to be introduced by internal flows within the cavity.

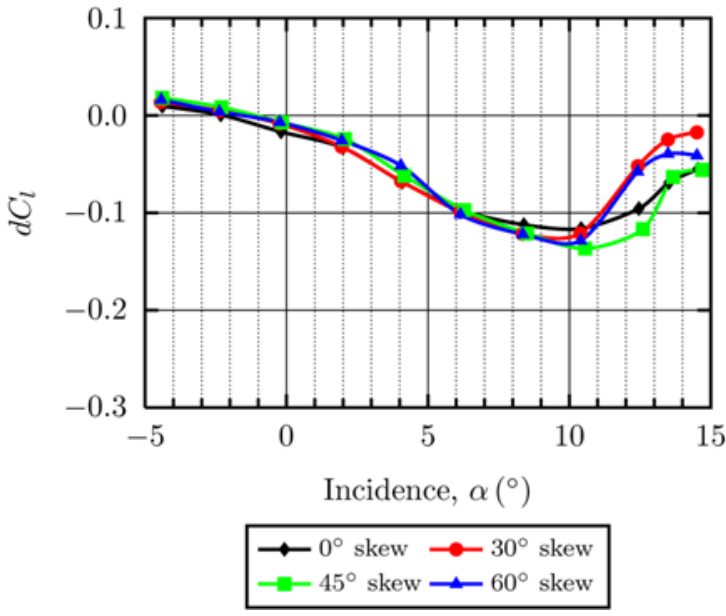

Figure 15. Lift coefficient increments for different skew angles

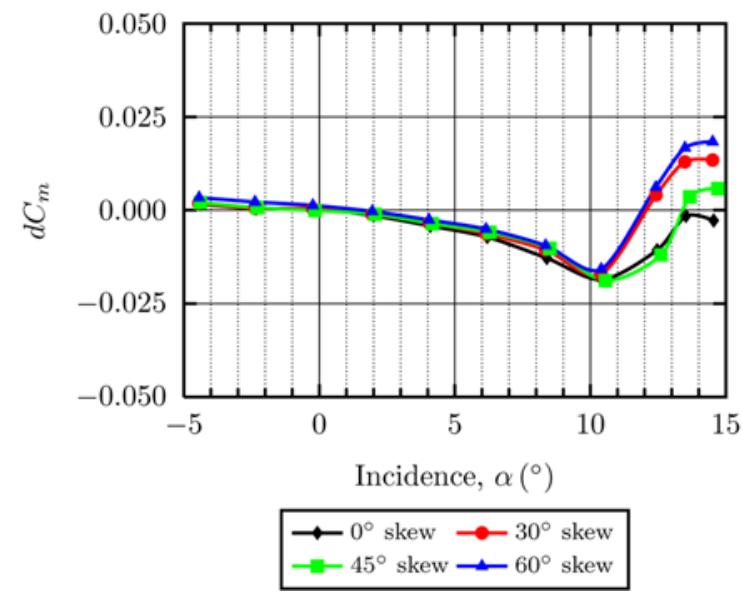

Figure 17. Pitching moment coefficient increments for different skew angles

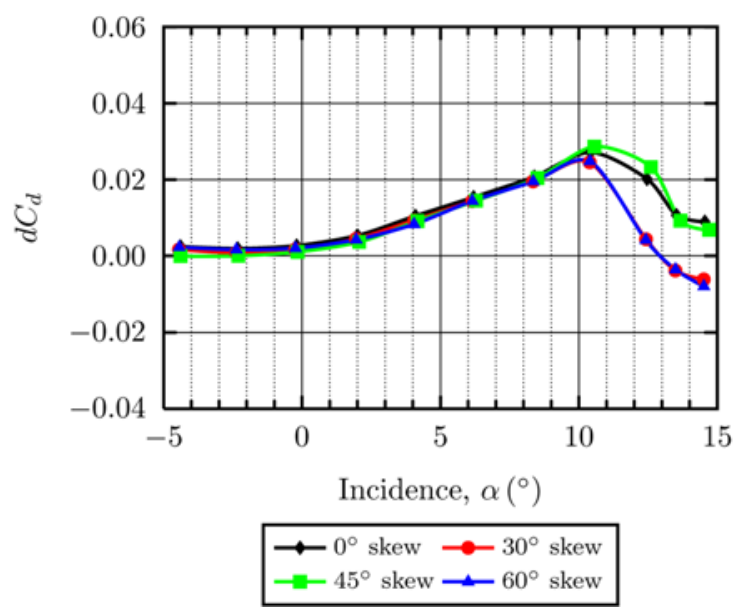

Figure 16. Drag coefficient increments for different skew angles

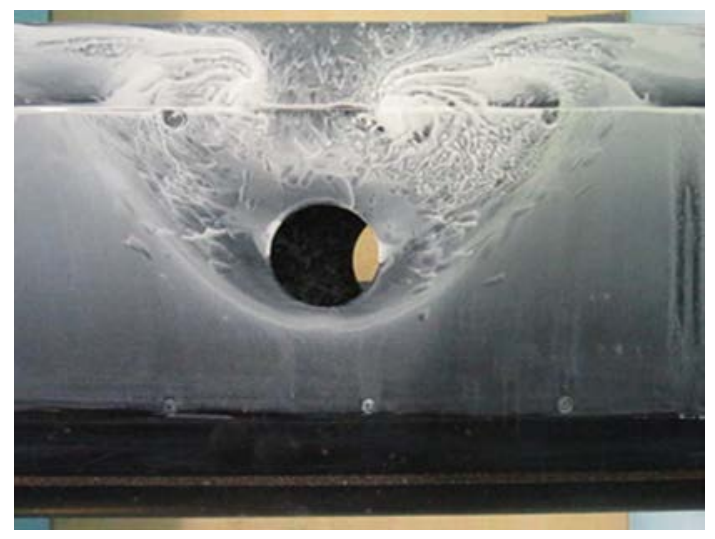

Figure 18. Flow visualisation on upper surface for $4^{\circ}$ skew. Incidence $=8^{\circ}$ 


\section{Combined Obliquity and Skew}

In reality, battle damage will be a combination of skew and obliquity, and for this reason wind tunnel tests were extended to consider $\pm 30^{\circ}$ obliquity with $30^{\circ}$ skew, and $\pm 60^{\circ}$ obliquity with $45^{\circ}$ skew. As seen for straight through damage, the addition of skew to obliquity produced no significant change in the increments, although there was always evidence of asymmetric flow through the damage when skew was present. The one exception to this trend was the $-60^{\circ}$ obliquity with $45^{\circ}$ skew combination. The coefficient increments for this combination are shown in Figs. 19 to 21 along with the straight through case (from Figs. 4, 6 and 7) and the $-60^{\circ}$ obliquity case (from Figs 10 to 12). As expected the most notable feature from the graphs is that the combined obliquity/skew case was consistently closer to the obliquity case than the straight through case. However, there were small but consistent differences between the combined and the obliquity cases. These differences occurred typically from about $2^{\circ}$ incidence where the damage jet was strong. This addition of skew to the obliquity case produced a change in the increments which was not previously seen when adding skew to the straight through case (Figs. 15 to 17). However, the differences in coefficient increments were not entirely consistent with a strengthening or weakening of the damage jet. For example, Fig. 19 showed that the

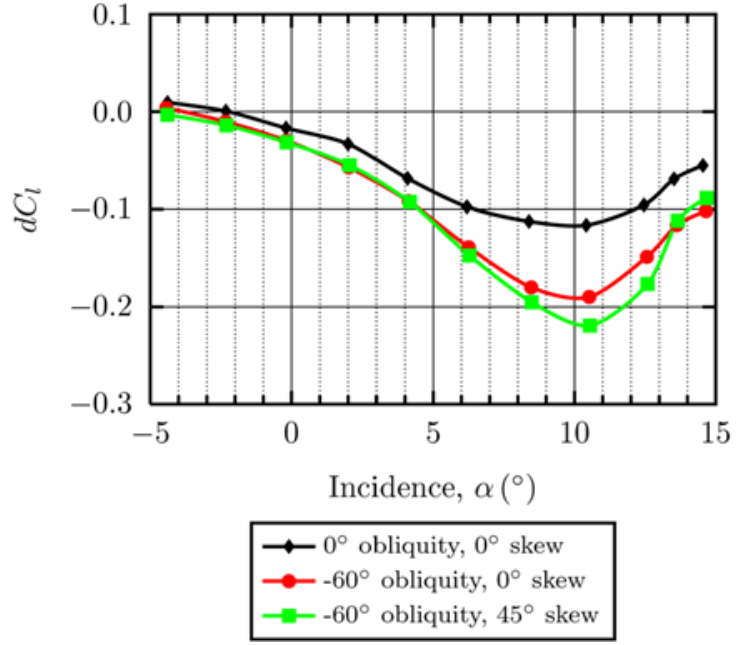

Figure 19. The influence of combined skew and obliquity on lift coefficient increments addition of skew resulted in a greater lift loss, which is consistent with a strengthening damage jet. However, Fig 20 indicates that a drag reduction occurred which is typical of a weakening jet. Although flow visualisation showed that asymmetry was present in the damage jet whenever skew was introduced, there was little evidence to suggest that the asymmetry became more pronounced with negative obliquity. However, it should be noted that with decreasing obliquity the damage jet strength increased and the damage wake was larger and covered a greater proportion of the model surface. Changes in the damage wake structure brought about by the flow asymmetry may be expected to have a small but increasingly significant effect on increments as the wake got larger with reduced obliquity.

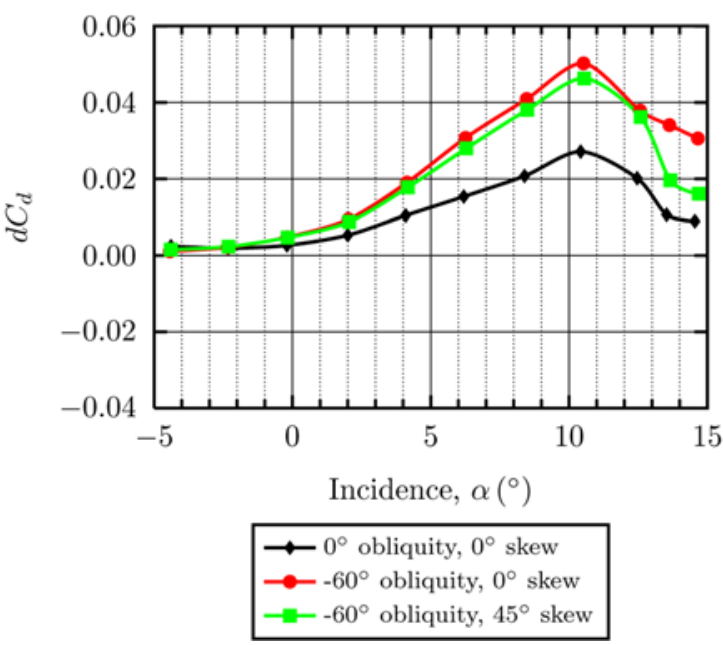

Figure 20. The influence of combined skew and obliquity on drag coefficient increments

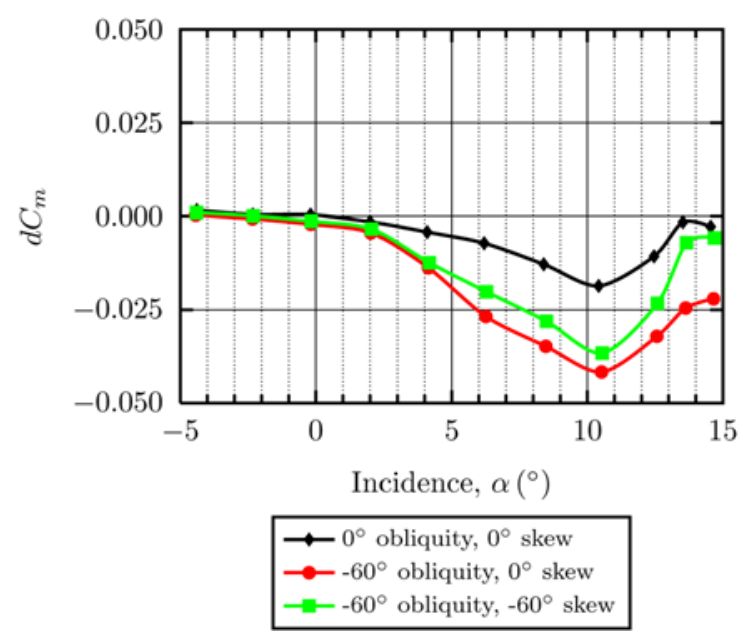

Figure 21. The influence of combined skew and obliquity on pitching moment coefficient increments 


\section{Conclusions}

1. The trends in aerodynamic coefficients due to battle damage, previously identified by Irwin, are applicable to other aerofoil geometries. These trends are: battle damage increases drag, reduces lift and makes the pitching moment more negative (i.e. nose down). Up to the onset of stall, these effects became more pronounced as incidence is increased.

2. The addition of negative obliquity (i.e. the upper surface hole is forward of the lower surface hole) resulted in more significant changes in the aerodynamic coefficients.

3. The addition of positive obliquity reduced the magnitude of changes in the aerodynamic coefficients.

4. Except for extreme negative obliquity angles, the addition of spanwise skew to the damage had little effect on the magnitude of the aerodynamic coefficients. However in all cases, the addition of skew resulted in asymmetry in the flow through the damage.

\section{Acknowledgments}

This work has been supported by BAE Systems as part of their contribution to the European BaToLUS project. The enthusiastic monitoring of the project by Dr. Andrew Irwin and Mark Lucking has been greatly appreciated by the authors. The help and expertise of Rob Hunter and Stacey Prentice in manufacturing the wind tunnel models is also appreciated.

\section{References}

${ }^{1}$ Irwin A.J and Render P.M. "The Influence of Mid-chord Battle Damage on the Aerodynamic Characteristics of Two-dimensional Wings,” The Aeronautical Journal, Vol.104, No. 1033, Paper No. 2432, March 2000.

${ }^{2}$ Mani, M., and Render, P.M., "Experimental Investigation into the Aerodynamic Effects of Airfoils with Triangular and Star Shaped Through Damage,” AIAA Paper 2005-4978, June 2005.

${ }^{3}$ Irwin A.J and Render P.M. "The Influence of Internal Structure on the Aerodynamic Characteristics of Battle Damaged Wings,” 14th AIAA Applied Aerodynamic Conference Proceedings, 1996. AIAA-1996-2395

${ }^{4}$ Garner H.C. Rogers E.W.E, Acum W.E.A,, and Maskell E.C. "Subsonic Wind Tunnel Corrections,” Technical Report AGARDograph 109, AGARD, October 1966

${ }^{5}$ McGhee R.J and. Beasley W.D. Wind-tunnel results for a modified 17-percent-thick low-speed airfoil section. NASA Technical Paper 1919, NASA Langley Research Centre, 1981. 